\title{
Morphological Characteristics of the Cranial Base of Early Angle's Class II Division 1 Malocclusion in Permanent Teeth
}

\author{
Características Morfológicas de la Base de Cráneo en la Maloclusión \\ Temprana Clase II División 1 de Angle en Dientes Permanentes
}

Xiu-Ping Wu; Jing Xuan; Han-yan Liu; Mei-rong Xue \& Li Bing

WU, X. P.; JING, X.; LIU, H. Y.; XUE, M. R. \& LI, B. Morphological characteristics of the cranial base of early angle's class II division 1 malocclusion in permanent teeth. Int. J. Morphol., 35(2):589-595, 2017.

SUMMARY: To investigate the effects of morphological characteristics of cranial base on malocclusion by analyzing characteristics of sagittal and vertical facial types of Angle's class II division 1 malocclusion so as to provide theoretical references for clinical diagnosis and correction of early Angle's class II division 1 malocclusion in permanent teeth. We randomly selected lateral radiographs of the skull of 80 patients at the age of 12-14 years old from the Department of Orthodontics, Stomatological Hospital, Shanxi Medical University, China. There were 20 cases of Angle's class I malocclusion with average angle, 20 cases of Angle's class II division 1 malocclusion with average angle, 20 cases of Angle's class II division 1 malocclusion with low angle, and 20 cases of Angle's class II division 1 malocclusion with high angle. Winceph 8.0 software was used to measure 39 hard tissue markers and 13 indicators reflecting the characteristics of cranial base structure. One-way t-test was used in the average-angle class II division 1 group and average-angle class I group. Least significant difference was utilized in patients with different vertical types of class II division 1 malocclusion.nterior (S-N) and posterior (S-Ba) cranial base lengths, and total cranial base length (Ba-N) were significantly longer in the class II division 1 patients compared with the class I patients. Significant differences in anterior cranial floor base angle (CF-PM), middle cranial floor base angle (Ba-SE-PM), and posterior cranial base inclination (SBa-FH) were determined between class II division 1 malocclusion and class I malocclusion patients. CF-PM angle and SBaFH were smaller in class II division 1 subjects than in class I subjects. Ba-SE-PM angle and cranial floor base angle (Ba-SE-FMS) were larger in class II division 1 subjects than in class I subjects. No significant difference in cranial base angle (N-S-Ba) and anterior cranial base inclination (SN-FH) was detected between class II division 1 subjects and class I subjects. Morphology of cranial base and cranial floor base has a significant effect on sagittal and vertical facial types of Angle's class II division 1 malocclusion. The changes in the length of the posterior skull base and the inclination of the anterior skull base are mainly presented in the sagittal direction. Angle of cranial base and cranial floor base plays a certain role in vertical facial type of Angle's class II division 1 malocclusion.

KEY WORDS: Cranial base; Class II division 1 malocclusion; Cephalometric measurements; Morphological characteristics.

\section{INTRODUCTION}

Craniofacial complex is composed of neurocranium, viscerocranium, and cranial base (Lewis et al.,1985; Enlow et al., 2007; van Limborgh et al., 2012). The cranial base is the main supporting structure in the midface. Björk proposed that the structure of cranial base determined the positional relationship between maxilla and mandible, and thought that the occurrence of malocclusion was associated with the structure of cranial base (Björk, 1955). Therefore, the characteristics of the structure of the cranial base have received the attention of orthodontic scholars. The abnormalities in growth and development of the cranial base may cause the occurrence of skeletal malocclusion or aggravate the degree of malocclusion. Understanding the morphological features of the cranial base contributes to early diagnosis and prediction of the occurrence, development and prognosis of dental malformations to lay a good foundation for a correct treatment plan (Baccetti et al., 1997; Ishii et al., 2002; Hayashi, 2003; Maurya et al., 2016).

There still has been lack of systematic study on effects of morphological characteristics of sagittal and vertical cranial base on the formation and development of Angle's class II division 1 malocclusion (Hsu et al., 2016; Nilsson et al., 2016; Shirazi et al., 2016). Thus, this study selected lateral radiographs of the skull of 80 patients at the age of 12 to 14 years (early permanent dentition), with an equal number of males and females. There were 20 cases of Angle's class I malocclusion with average angle (average-angle class I group), 
20 cases of Angle's class II division 1 malocclusion with average angle (average-angle class II division 1 group), 20 cases of Angle's class II division 1 malocclusion with low angle (low-angle class II division 1 group), and 20 cases of Angle's class II division 1 malocclusion with high angle (high-angle class II division 1 group). We compared morphological characteristics of the cranial base in children with different craniofacial types in growth and development period, fully analyzed the effects of morphological characteristics of the cranial base on sagittal and vertical facial types of Angle's class II division 1 malocclusion, investigated the positional relationship of morphology of the cranial base with maxilla and mandible, and provided a reference for prediction, early diagnosis and treatment of facial growth of malocclusion patients.

\section{MATERIAL AND METHOD}

Case collection.We randomly selected eighty patients aged 12-14 years old from the Department of Orthodontics, Stomatological Hospital, Shanxi Medical University, China, with an equal number of males and females. The patients were equally assigned to average-angle class I group, high-angle class II division 1 group, low-angle class II division 1 group, and average-angle class II division 1 group. Lateral skull radiographs were taken. Inclusion criteria: (1) Angle's class I: neutral molar and canine relationship, normal coverage of overbite of anterior teeth, $0^{\circ} \leq \mathrm{A}$ point-nasion-B point angle (ANB) $\leq 4^{\circ}$, average angle $\left(22^{\circ}<\right.$ FH-MP $<32^{\circ} ; 29^{\circ}<$ SN-MP $<40^{\circ}$ ); Angle's class II division 1: distal molar relationship on both sides, ANB angle $>4^{\circ}$. (2) In accordance with vertical relationship between the maxilla and mandible, Angle's class II division 1 was classified into high-angle group (SN-MP $>40^{\circ}$; FH-MP $\left.>32^{\circ}\right)$, average-angle group $\left(22^{\circ}<\mathrm{FH}-\right.$ $\mathrm{MP}<32^{\circ} ; 29^{\circ}<\mathrm{SN}-\mathrm{MP}<40^{\circ}$ ), and low-angle group (FH$\mathrm{MP}<22^{\circ} ; \mathrm{SN}-\mathrm{MP}<40^{\circ}$ ). (3) Occlusal and bone types were consistent between Angle's class II division 1 and Angle's class I patients. (4) Han nationality, good health, normal maxillary and mandibular development, without history of temporomandibular disorders, without disease affecting the development of stomatognathic system, facial symmetry, no history of trauma. (5) No orthodontic treatment. (6) Early permanent dentition; the second molar has erupted; no congenital absence of teeth or tooth extraction.

Instruments and equipment.There were head positioning $\mathrm{X}$-ray camera (Siemens, Germany) and Winceph 8.0 cephalometric analysis system (Rise, Japan).

Lateral radiographs of the skull. (1) All patients were photographed by the same technician from the Department of Radiology of our hospital with the head positioning X-ray camera under the same condition. (2) The subject stood erect and looked straight ahead. With the head positioning X-ray camera, in intercuspal position, the face relaxed. The sagittal plane was parallel to the cassette. Lateral radiographs of the skull randomly selected from different groups are shown in Figure 1.
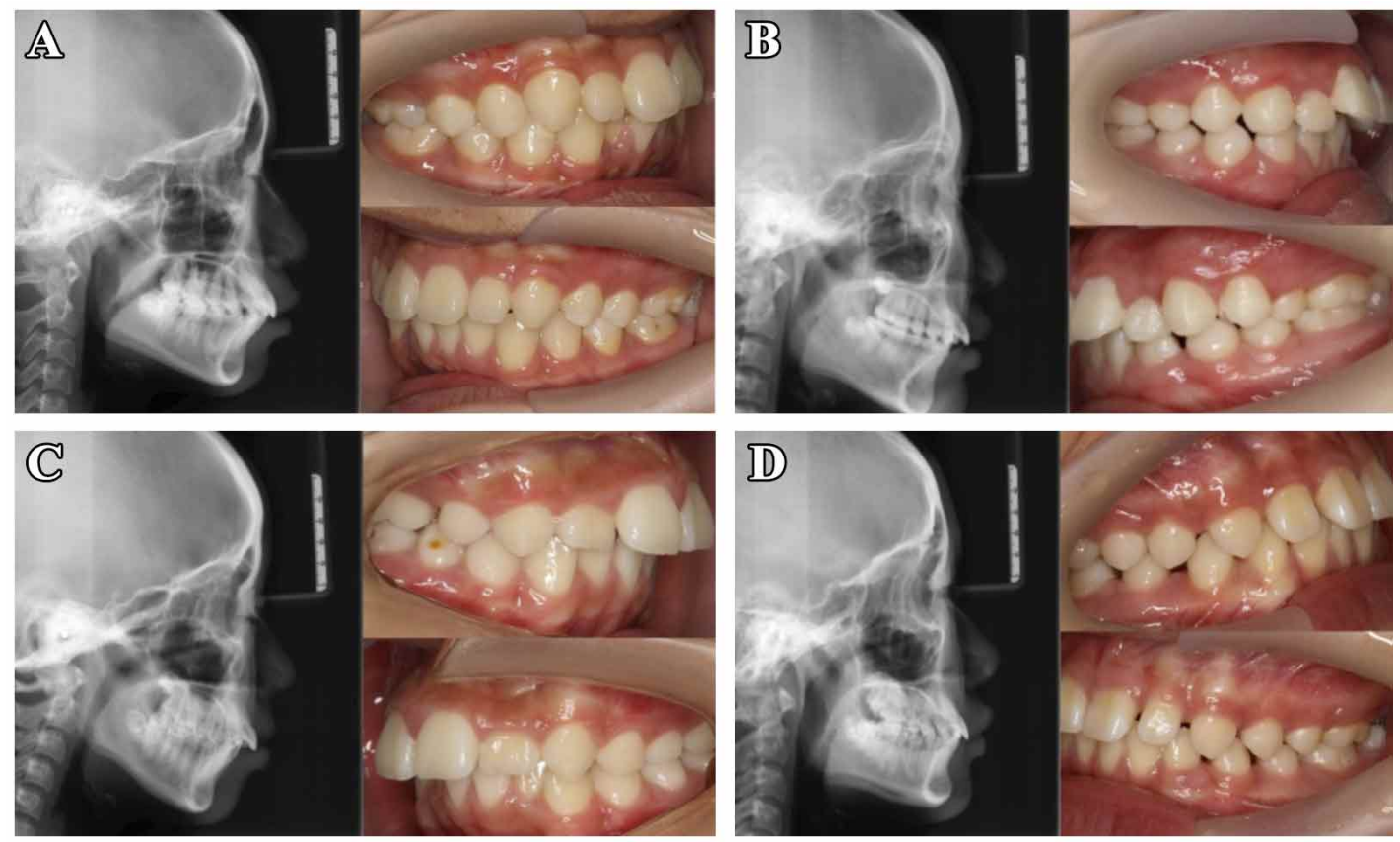

Fig. 1 A. Average-angle Angle's class I. B. Average-angle Angle's class II division 1. C.High-angle Angle's class II division 1. D.Low-angle Angle's class II division 1 
Determining the marking point and reference plane.Lateral radiographs of the skull were introduced into the Winceph 8.0 software. Cephalometric measurements were repeated three times by the same researcher at different times. The average value was calculated. The marking points are as follows (Figs. 2 and 3).

Cranial base-related measurement items. (1) S$\mathrm{N}$ : Anterior cranial base length, the distance between sella turcica and nasion; (2) S-Ba: posterior cranial base length, the distance between sella turcica and basion; (3) Ba-N: total cranial base length, the distance between nasion and basion; (4) N-S-Ba: cranial base angle, the angle between anterior and posterior skull base planes, representing skull base curvature; (5) S-Ar-Go ${ }^{\circ}$ joint angle; (6) SN-FH: anterior cranial base inclination, the angle between anterior skull base plane and orbital plane; (7) SBa-FH: posterior cranial base inclination, the angle between posterior skull

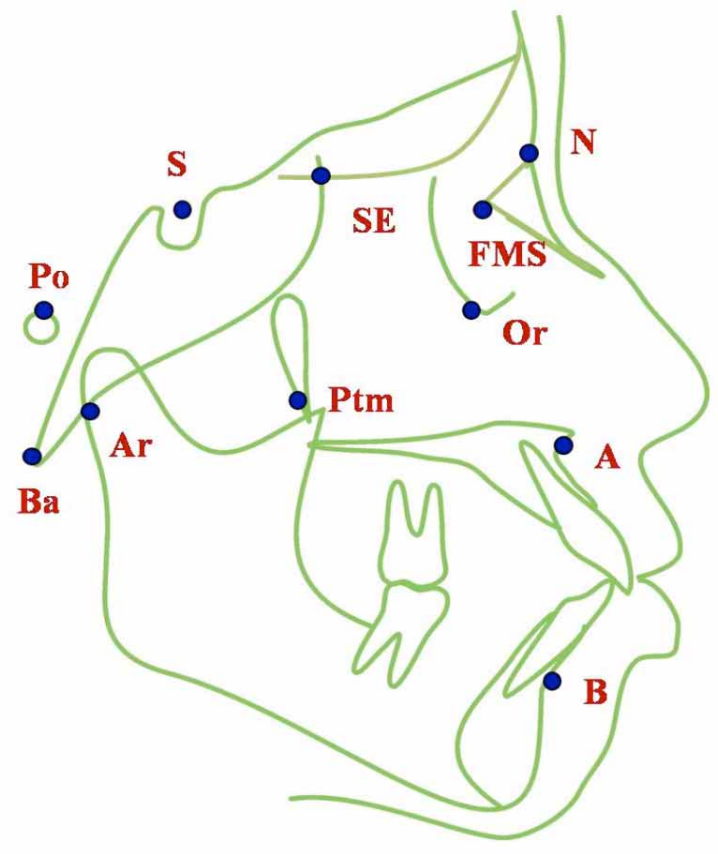

Fig. 2. Cranial marking points. S: Center of the image of the sella turcica; N: nasion, the most anterior point of nasofrontal suture, representing facial and cranial junction; Po: mechanical ear point, the top point of the earpiece image of the positioning instrument; $\mathrm{Ba}$ : basion, midpoint of anterior margin of foramen magnum; $\mathrm{O}$ : orbitale, the lowest point of the infraorbital rim; Ptm: pterygomaxillary fissure point, the lowest point of the maxillary cleft contour; A: subspinale, the most concave point of bone structure between the anterior nasal spine and superior prosthion; Ar: articulare, intersection of the lower edge of skull base and the posterior margin of mandibular condyle; B: supramental, the most concave point of bone structure between infradentale and pogonion; SE: sphenethmoid, the intersection of greater wing of sphenoid bone and the anterior cranial base; FMS: maxillofrontal suture, the last point of nasofrontal suture base plane and orbital plane; (8) Ba-SE-FMS: cranial floor base angle, representing the opening degree of cranial floor base; (9) Ba-SE-PM: middle cranial floor base angle, representing the inclination ofmiddle cranial floor base plane; (10) CF-PM: anterior cranial floor base angle, representing the inclination of anterior cranial floor base plane; (11) S-N-A: sella-nasion-point A angle, representing the positional relationship (anterior and posterior) of the maxilla with respect to the skull; (12) S-N-B: sella-nasionpoint $B$ angle, representing the positional relationship (anterior and posterior) of the mandible relative to the skull; (13) A-N-B: AB plane angle, representing the positional relationship of the maxilla and mandible to the skull.

Statistical analysis. Data were analyzed with SPSS 17.0 software. One-way t-test and least significant difference were used to analyze 13 cephalometric measurements between average-angle class II division 1 group and average-angle class I group, among high-angle, low-angle, average-angle class II division 1 groups. The significance level was $\mathrm{a}=0.05$. A value of $\mathrm{P}<0.05$ was considered statistically significant. A value of $\mathrm{P}<0.01$ was considered extremely statistically significant.

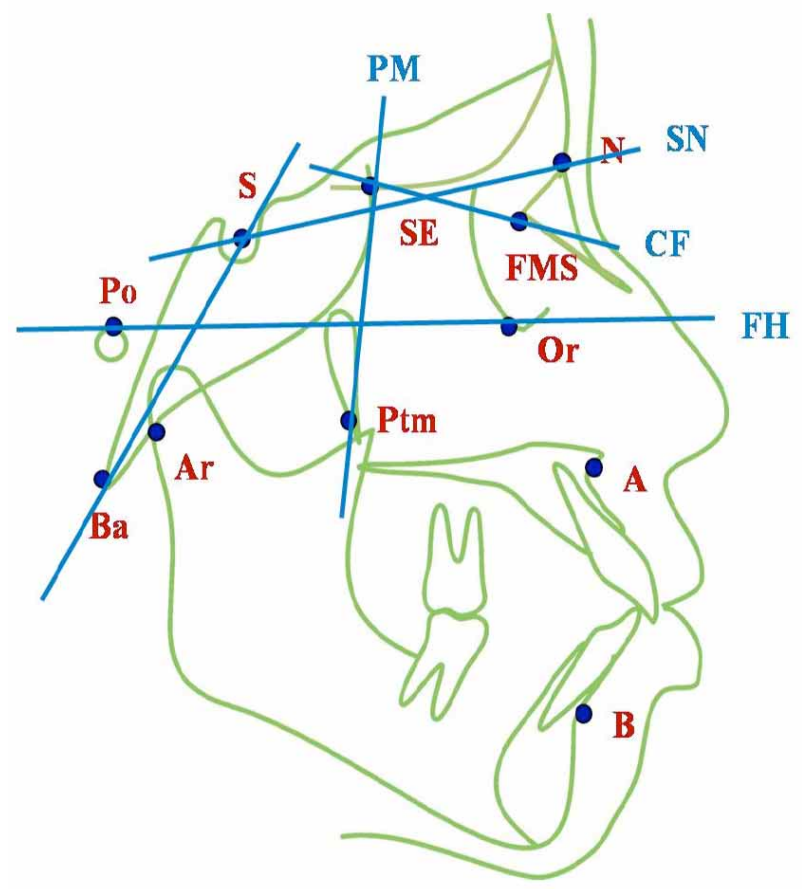

Fig. 3. Cranial measurement plane. FH plane: orbitomeatal plane, the connection between orbitale and mechanical ear point; SN plane: Anterior cranial base plane, the connection between nasion and sella turcica; PM plane: the connection between SE and Ptm; S-Ba plane: Posterior cranial base plane, the connection between sella turcica and cranial base; CF plane: the connection between SE and FMS 


\section{RESULTS}

(1) Posterior cranial base length $\mathrm{S}-\mathrm{Ba}$, anterior cranial base length $\mathrm{S}-\mathrm{N}$, and total cranial base length $\mathrm{Ba}-\mathrm{N}$ were significantly longer in the class II division 1 patients than in the class I patients. Significant differences in anterior cranial floor base angle CF-PM, middle cranial floor base angle $\mathrm{Ba}-\mathrm{SE}-\mathrm{PM}$, posterior cranial base inclination $\mathrm{SBa}-\mathrm{FH}$, and cranial floor base angle Ba-SE-FMS were determined between class II division 1 malocclusion and class I malocclusion patients. CF-PM angle and SBa-FH were smaller in class II division 1 subjects than in class I subjects $(\mathrm{P}<0.05)$. Ba-SE-PM angle and Ba-SE-FMS angle were larger in class II division 1 subjects than in class I subjects $(\mathrm{P}<0.05)$. No significant difference in sella-nasion-point $\mathrm{A}$ angle (SNA), sella-nasion-point B angle (SNB), cranial base

Table. I. Comparison of cephalometric measurements between Angle's class II division 1 and Angle's class I patients $(\mathrm{x} \pm \mathrm{s})$

\begin{tabular}{lll}
\hline Items (unit) & Class I & Class II division 1 \\
\hline $\mathrm{S}-\mathrm{N}(\mathrm{mm})$ & $70.09 \pm 204.37$ & $73.30 \pm 2.94^{*}$ \\
$\mathrm{~S}-\mathrm{Ba}(\mathrm{mm})$ & $43.61 \pm 3$. & $47.46 \pm 2.92^{*}$ \\
$\mathrm{~N}-\mathrm{Ba}(\mathrm{mm})$ & $109.29 \pm 7.74$ & $111.73 \pm 6.27^{*}$ \\
$\mathrm{~N}-\mathrm{S}-\mathrm{Ba}\left({ }^{\circ}\right)$ & $130.26 \pm 3.64$ & $131.45 \pm 4.74$ \\
$\mathrm{~S}-\mathrm{Ar}-\mathrm{Go}{ }^{\circ}$ & $140.45 \pm 6.38$ & $145.37 \pm 3.28$ \\
$\mathrm{SN}-\mathrm{FH}\left({ }^{\circ}\right)$ & $4.58 \pm 2.89$ & $4.76 \pm 4.43$ \\
$\mathrm{SBa}-\mathrm{FH}\left({ }^{\circ}\right)$ & $52.39 \pm 4.11$ & $50.49 \pm 3.57 *$ \\
$\mathrm{Ba}-\mathrm{SE}-\mathrm{FMS}\left({ }^{\circ}\right)$ & $140.15 \pm 4.55$ & $138.20 \pm 7.33 *$ \\
$\mathrm{Ba}-\mathrm{SE}-\mathrm{PM}\left({ }^{\circ}\right)$ & $42.64 \pm 4.75$ & $50.49 \pm 3.57 *$ \\
$\mathrm{CF}-\mathrm{PM}$ & $100.14 \pm 6.53$ & $95.54 \pm 6.98 *$ \\
$\mathrm{SNA}$ & $81.27 \pm 3.46$ & $81.51 \pm 3.63$ \\
$\mathrm{SNB}$ & $77.46 \pm 2.88$ & $76.34 \pm 3.56$ \\
$\mathrm{ANB}$ & $3.81 \pm 2.89^{*}$ & $5.17 \pm 3.38^{*}$ \\
\hline
\end{tabular}

angle N-S-Ba and anterior cranial base inclination SN-FH was detected between class II division 1 subjects and class I subjects $(\mathrm{P}>0.05$; Table I).

(2) Significant differences in S-Ba length were detectable between high-angle class II division 1 group and averageangle and low-angle class II division 1 groups $(\mathrm{P}<0.05)$. No significant difference in $\mathrm{S}-\mathrm{N}$ length and $\mathrm{Ba}-\mathrm{N}$ length was determined among high-angle, average-angle and low-angle class II division 1 groups (P > 0.05). N-S-Ba angle, SN-FH inclination, CF-PM angle, and Ba-SE-PM angle were significantly larger in the high-angle class II division 1 group than in the low-angle and average-angle class II division 1 groups $(\mathrm{P}<0.05)$. However, there was no significant difference in N-S-Ba angle, SN-FH inclination, CF-PM angle, and $\mathrm{Ba}-\mathrm{SE}-\mathrm{PM}$ angle between the low-angle and average-angle class II division 1 groups $(\mathrm{P}>0.05)$. Significant differences in Ba-SE-FMS angle were found between the high-angle and low-angle class II division 1 groups $(\mathrm{P}<0.05)$. Nevertheless, no significant difference in Ba-SE-FMS angle was seen between the low-angle and average-angle class II division 1 groups, and the high-angle and average-angle class II division 1 groups ( $\mathrm{P}>0.05)$. There was no significant difference in SNA angle among high-angle, average-angle, and low-angle class II division 1 groups. There were significant differences in SNB angle between high-angle and average-angle class II division 1 groups $(\mathrm{P}<0.05)$. There were significant differences in ANB angle among high-angle, lowangle and average-angle class II division 1 groups ( $\mathrm{P}<0.05)$, but there was no significant difference in ANB angle between low-angle and average-angle class II division 1 groups (P>0.05; Table II).

Table. II. Comparison of cephalometric measurements of different vertical types of Angle's class II division $1(\mathrm{x} \pm \mathrm{s})$

\begin{tabular}{llll}
\hline Items (unit) & High-angle & Low-angle & Average-angle \\
\hline $\mathrm{S}-\mathrm{N}(\mathrm{mm})$ & $71.04 \pm 5.32$ & $68.30 \pm 5.94$ & $73.30 \pm 2.94$ \\
$\mathrm{~S}-\mathrm{Ba}(\mathrm{mm})$ & $43.50 \pm 3.38 \Delta^{*}$ & $49.56 \pm 4.24 \Delta$ & $47.46 \pm 2.92^{*}$ \\
$\mathrm{~N}-\mathrm{Ba}(\mathrm{mm})$ & $109.56 \pm 5.65$ & $107.34 \pm 8.81$ & $111.73 \pm 6.27$ \\
$\mathrm{~N}-\mathrm{S}-\mathrm{Ba}\left({ }^{\circ}\right)$ & $136.23 \pm 3.49^{*} \Delta$ & $133.47 \pm 5.83 \Delta$ & $131.45 \pm 4.74^{*}$ \\
$\mathrm{~S}-\mathrm{Ar}-\mathrm{Go}{ }^{\circ}$ & $148.34 \pm 9.54 \Delta$ & $143.59 \pm 3.64 \Delta$ & $145.37 \pm 3.28$ \\
$\mathrm{SN}-\mathrm{FH}\left({ }^{\circ}\right)$ & $7.35 \pm 2.68^{*} \Delta$ & $5.53 \pm 2.57 \Delta$ & $4.76 \pm 4.43^{*}$ \\
$\mathrm{SBa}-\mathrm{FH}\left({ }^{\circ}\right)$ & $52.45 \pm 5.23$ & $51.58 \pm 3.65$ & $50.49 \pm 3.57$ \\
$\mathrm{CF}-\mathrm{PM}\left({ }^{\circ}\right)$ & $98.21 \pm 3.32^{*} \Delta$ & $94.89 \pm 8.11 \Delta$ & $95.54 \pm 6.98^{*}$ \\
$\mathrm{Ba}-\mathrm{SE}-\mathrm{PM}\left({ }^{\circ}\right)$ & $38.48 \pm 2.98^{*} \Delta$ & $44.15 \pm 3.59 \Delta$ & $42.94 \pm 2.74$ \\
$\mathrm{Ba}-\mathrm{SE}-\mathrm{FMS}\left({ }^{\circ}\right)$ & $136.69 \pm 7.07 \Delta$ & $139.04 \pm 3.18 \Delta$ & $138.48 \pm 2.26$ \\
$\mathrm{SNA}$ & $80.94 \pm 2.53$ & $82.60 \pm 4.44$ & $81.51 \pm 3.63$ \\
$\mathrm{SNB}$ & $74.53 \pm 4.78^{*}$ & $78.26 \pm 6.34$ & $76.34 \pm 3.56^{*}$ \\
ANB & $6.41 \pm 3.25^{*} \Delta$ & $4.34 \pm 5.64 \Delta$ & $5.17 \pm 3.38^{*}$ \\
\hline
\end{tabular}

$\mathrm{P}<0.05$, statistical significance; $*$ high-angle group and average-angle group; $\Delta$ : highangle group and low-angle group;*: average-angle group and low-angle group 


\section{DISCUSSION}

Cephalometric roentgenogram is an important means widely used in the analysis of maxillofacial deformity (Wilhelm et al., 2001; Agarwal et al., 2013; Farooq et al., 2016). Sella turcica (S), nasion (N), basion (Ba), articulare (Ar) and Bolton are commonly used as cranial landmarks in the study of the skull base structure. Sphenethmoid (SE) is a clear anatomical marker and a landmark of anterior cranial fossa and middle cranial fossa. It is stable. Therefore, this study selected SE as a marker. The measurement of Ba-SEFMS angle and Ba-SE-PM angle can analyze the opening degree of the cranial floor base and the inclination of middle cranial floor base plane. Solow found that there was a significant correlation between the measured values taking $\mathrm{Ba}$ and $\mathrm{Ar}$ points as the markers of posterior cranial base. Thus, this study used cephalometric roentgenogram that could easily identify $\mathrm{Ba}$, and measured N-S-Ba angle and S-Ba length to study posterior cranial base, but did not use Ar to avoid the error caused by the analysis of posterior cranial base because of the changes in mandibular position. Anterior cranial base plane is considered a relative stable plane in cephalometric roentgenogram, and commonly used as an orientation plane of facial structure in relation to the cranial base. PM plane is the connection between sphenethmoid (SE) and pterygomaxillary fissure (Ptm), and the extremely important plane to understand the basic structure of craniofacial complex and its development. This study is designed to fully reflect the developmental characteristics of the cranial base by measuring 13 items, such as CF-PM angle, Ba-SE-PM angle, and SBa-FH inclination.

Björk thought that the location of the maxilla and mandible was determined by the structure of the cranial base, and proposed that the structure of the cranial base was associated with the development of malocclusion. Some scholars believed that the size of the cranial base angle affected the location of the maxilla and mandible, and then induced sagittal malocclusion (Lestrel et al., 2013; AL-Nimri et al., 2016; Zervas et al., 2016). Other scholars considered that one of the mechanisms of Angle's class II malocclusion was the increase of $\mathrm{N}-\mathrm{S}-\mathrm{Ba}$ angle, which caused the retrusion of the mandible and the relative protrusion of the maxillary complex (Brenda et al., 2001; Janson et al., 2016). However, some scholars confirmed that the N-S-Ba angle in Angle's class II malocclusion patients did not enlarge, and did not strongly associated with the position of the mandible. We found that there was no significant difference between Angle's class II and class I malocclusions. Nevertheless, S$\mathrm{Ba}$ length and $\mathrm{Ba}-\mathrm{N}$ length were significantly longer, but $\mathrm{S}$ $\mathrm{N}$ length was significantly shorter in the class II division 1 patients than in the class I patients, indicating significant differences in the cranial base length between them. In this study, we selected average-angle patients with normal vertical facial type. Thus, to a certain extent, we excluded the situation that vertical craniofacial growth compensates for abnormal sagittal growth. Compared with Angle's class I malocclusion patients, besides the difference in cranial base length, CF-PM angle and posterior cranial base inclination SBa-FH were smaller, but Ba-SE-PM angle and S-Ba length were larger in Angle's class II malocclusion patients. As shown in Table I, S-Ba length increased, Ba-SE-PM angle increased, and $\mathrm{SBa}-\mathrm{FH}$ reduced, which induced $\mathrm{Ba}$ point moved backward, possibly caused mandibular retrusion of Angle's class II division 1 malocclusion. Simultaneously, CF-PM angle was smaller in Angle's class II patients than in Angle's class I patients, i.e., short anterior cranial base, suggesting the anterior cranial floor base slopes downwards. Accompanied by the increased middle cranial floor base angle and backward downward inclination of the posterior cranial base, these probably are the reasons for nonsignificant difference in N-S-Ba angle between Angle's class II and class 1 malocclusions. These findings suggested that the growth of anterior and posterior cranial bases and rotation of cranial base plane had a certain effect on positional relationship between sagittal maxilla and mandible. Therefore, we should pay attention to the morphological characteristics of the cranial base during analyzing the relationship between maxilla and mandible.

Our results demonstrated that anterior cranial base inclination SN-FH was significantly larger in the high-angle class II division 1 group than in the average-angle and lowangle class II division 1 groups, which indicated that the anterior cranial base of high-angle patients had an upward forward rotation. However, no significant difference in anterior cranial base inclination SN-FH was determined between the class II division I and class I patients, but there were significant differences in anterior cranial base length between them. Above results possibly showed that the inclination of anterior cranial base plane $\mathrm{SN}$ had a certain effect on the mechanism of class II division 1 malocclusion patients with abnormal vertical facial type. Moreover, the anterior cranial base length certainly affected the abnormal sagittal facial type of class II division 1 malocclusion. In this study, cranial floor base angle Ba-SE-FMS reflects the opening degree of the cranial floor base. CF-PM angle reflects remarkably increased anterior cranial floor base inclination in the high-angle class II division 1 group, suggesting that high-angle anterior cranial floor base had an upward forward rotation. Middle cranial floor base angle $\mathrm{Ba}-\mathrm{SE}-\mathrm{PM}$ increased in the low-angle and average-angle class II division 1 groups, reflecting middle cranial floor base plane inclination, and indicating the downward forward 
inclination of middle cranial floor base in the low-angle and average-angle class II division 1 groups.

Results from this study demonstrated that cranial base angles, SNA and SNB were not significantly different between the class II and class I, which suggested that there may be some compensatory complementary mechanisms for the positional relationship of the cranial base structure with maxilla and mandible. In this study, SN-FH was not significantly different between class II and class I, which indicated that anterior cranial base inclination was not the reason for sagittal difference in the maxilla and mandible. The plane $\mathrm{SN}$ is relatively a stable reference plane, but from a geometric point of view, S-N inclination is negatively associated with the SNA angle. During cephalometric analysis, it is necessary to take into account the compensatory change in SNA angle that occurs due to variations in the S$\mathrm{N}$ plane tilt in individual cases to avoid one-sidedness judgment. Briefly, the S-N plane is relatively constant on the whole; but there may be a large variation for different individuals. Moreover, this variation may also affect the size of the SNA angle. Therefore, during the analysis of the mechanisms responsible for class II division 1 malocclusion, it is necessary to combine the slope of the $\mathrm{S}-\mathrm{N}$ plane so as to judge the significance of SNA angle measurements. In this study, SNA and SNB were not significantly different, but ANB was significantly different between class II and class I, indicating that ANB could reflect the relative position of the maxilla and the mandible in relation to the skull.

This study analyzed the effects of sagittal and vertical facial types on the formation of Angle's class II malocclusion. Results demonstrated that anterior cranial base inclination SN-FH significantly increased in the high-angle Angle's class II group compared with the average-angle and low-angle Angle's class II groups. Anterior cranial base length S-N was not significantly different among high-angle, low-angle and average-angle Angle's class II groups. Abovementioned results verified that anterior cranial base rotated upward forward, but its length was not altered in high-angle patients. On the contrary, the rotation of anterior cranial base probably affected the vertical growth of Angle's class II. Anterior cranial floor base angle CF-PM reflects the degree of anterior cranial floor base inclination. CF-PM angle was significantly larger in the high-angle Angle's class II group than in the average-angle and low-angle Angle's class II groups $(\mathrm{P}<0.05)$, which further indicated that the anterior cranial floor base possibly rotated forwards upwards. Angle's class II division 1 reflects middle cranial floor base angle Ba-SE-PM of the middle cranial floor base inclination. BaSE-PM angle was significantly increased in the low-angle and average-angle Angle's class II groups ( $\mathrm{P}<0.05)$, indicating that middle cranial floor base sloped forwards downwards in Angle's class II with low and average angles. Cranial base angle N-S-Ba was significantly different among high-, average-, and low-angle Angle's class II groups, but not significantly different between class II and class I groups. These results probably confirmed that anterior $(\mathrm{S}-\mathrm{N})$ and posterior $(\mathrm{S}-\mathrm{Ba})$ cranial base lengths affected vertical development of maxilla and mandible, but did not significantly affect the mechanism of sagittal formation of Angle's class II. Furthermore, Ba-SE-FMS angle reflects the opening degree of cranial floor base in the high-angle Angle's class II group. Ba-SE-FMS angle was significantly different between class II and class I, but N-S-Ba angle was not significantly different between them, suggesting that cranial floor base possibly affected the sagittal formation of Angle's class II. Ba-SE-FMS angle was significantly different among high-, low-, and average-angle Angle's class II groups. Above-described findings confirmed that cranial floor base affected the vertical development of Angle's class II.

In summary, morphological characteristics of growth and development of the cranial base, especially cranial floor base, affect the sagittal and vertical growths of Angle's class II. In the clinic, during the analysis of formation mechanisms for Angle's class II malocclusion, we not only consider the positional relationship between maxilla and mandible, but also pay attention to the changes in the cranial base and cranial floor base so as to objectively evaluate the etiology, diagnosis and prognosis of Angle's class II malocclusion.

WU, X. P.; JING, X.; LIU, H. Y.; XUE, M. R. \& LI, B. Características morfológicas de la base de cráneo en la maloclusión temprana clase ii división 1 de angle en dientes permanents. Int. J. Morphol., 35(2):589-595, 2017.

RESUMEN: El objetivo de este trabajo consistió en investigar los efectos de las características morfológicas de la base craneal sobre la maloclusión, a través del análisis de los siferentes tipos faciales de maloclusión Clase II de Angle (sagital y vertical), para proporcionar referencias teóricas para el diagnóstico clínico y la corrección temprana de la maloclusión de clase II división 1 de Angle en dientes permanentes. Se seleccionaron al azar radiografías laterales de cráneo de 80 pacientes, entre 12-14 años de edad, del Departamento de Ortodoncia, Hospital de Estomatología, Universidad Médica de Shanxi, China. Hubo 20 casos de maloclusión clase I de Angle con ángulo promedio, 20 casos de maloclusión clase II de Angle con ángulo promedio, 20 casos de maloclusión Clase II de Angle con ángulo bajo y 20 casos de maloclusión clase 1 de Angle con ángulo alto. Se utilizó el software Winceph 8.0 para medir 39 marcadores de tejido duro y 13 indicadores que reflejan las características de la estructura de la base de cráneo. Se usó la prueba t de una vía en el grupo clase II de división 1 con ángulo promedio y el grupo clase I con ángulo promedio. Se detectaron diferencias mínimas significativas en pacien- 
tes con diferentes tipos verticales de maloclusión clase II división 1. Las longitudes de la base de cráneo posterior $(\mathrm{SN})$ y posterior (S-Ba), y la longitud total de la base craneal (Ba-N) fueron significativamente mayores en la clase II, en comparación con los pacientes de la clase I. Se determinaron diferencias significativas en el ángulo de la base del piso craneal anterior (CF-PM), el ángulo de la base del piso craneal medio (Ba-SE-PM) y la inclinación de la base craneana posterior (SBa-FH) entre la maloclusión clase II división 1 y los pacientes con maloclusión de clase I. Los ángulos de CF-PM y SBa-FH fueron más pequeños en la clase II división 1 que en la clase I. El ángulo de Ba-SE-PM y el ángulo de base del piso craneal (Ba-SE-FMS) fueron mayores en sujetos de clase II división 1 que en sujetos de clase I. No se detectaron diferencias significativas en el ángulo de la base craneana (N-S-Ba) y la inclinación de la base craneal anterior (SN-FH) entre los sujetos de la clase II división 1 y los de la clase I. La morfología de la base craneal y de la base del suelo craneal tiene un efecto significativo en los tipos faciales sagital y vertical de maloclusión Clase II división 1 de Angle. Los cambios en la longitud de la base posterior del cráneo y la inclinación de la base anterior del cráneo se presentaron principalmente en la dirección sagital. El ángulo de la base craneal y la base del suelo craneal tiene cierto rol en el tipo facial vertical de la clase II de Angle.

PALABRAS CLAVE: Base craneal; Clase II división 1 maloclusión; Mediciones cefalométricas; Características morfológicas.

\section{REFERENCES}

Agarwal, A.; Pandey, H.; Bajaj, K. \& Pandey, L. Changes in cranial base morphology in class i and class ii division 1 malocclusions. J. Int. Oral Health, 5(1):39-42, 2013.

Al-Nimri, K.; Abo-Zomor, M. \& Alomari, S. Changes in mandibular position in treated Class II division 2 malocclusions in growing and non-growing subjects. Aust. Orthod. J., 32(1):73-81, 2016.

Baccetti, T.; Antonini, A.; Franchi, L.; Tonti, M. \& Tollaro, I. Glenoid fossa position in different facial types: a cephalometric study. Br. J. Orthod., 24(1):55-9, 1997.

Björk, A. Cranial base development: A follow-up x-ray study of the individual variation in growth occurring between the ages of 12 and 20 years and its relation to brain case and face development. Am. J. Orthod., 41(3):198-225, 1955.

Enlow, D. H.; Kuroda, T. \& Lewis, A. B. The morphological and morphogenetic basis for craniofacial form and pattern. Angle Orthod., 41(3):161- 88, 2007.

Farooq, M. U.; Khan, M. A.; Imran, S.; Sameera, A.; Qureshi, A.; Ahmed, S. A.; Kumar, S. \& Rahman, M. A. Assessing the reliability of digitalized cephalometric analysis in comparison with manual cephalometric analysis. J. Clin. Diagn. Res., 10(10):ZC20-3, 2016.

Hayashi, I. Morphological relationship between the cranial base and dentofacial complex obtained by reconstructive computer tomographic images. Eur. J. Orthod., 25(4):385-91, 2003.

Hsu, Y. L.; Chang, C. H. \& Roberts, W. E. Canine-lateral incisor transposition: Controlling root resorption with a bone-anchored T-loop retraction. Am. J. Orthod. Dentofacial Orthop., 150(6):1039-50, 2016.

Ishii, N.; Deguchi, T. \& Hunt, N. P. Morphological differences in the craniofacial structure between Japanese and Caucasian girls with Class II Division 1 malocclusions. Eur. J. Orthod., 24(1):61-7, 2002.
Janson, G.; Niederberger, A.; Garib, D. G. \& Caldas, W. Root resorption in Class II malocclusion treatment with Class II elastics. Am. J. Orthod. Dentofacial Orthop., 150(4):585-91, 2016.

Lestrel, P. E.; Bodt, A. \& Swindler, D. R. Longitudial study of cranial base shape changes in Maraca nemestrina. Am. J. Phys. Anthropo1., 91:11729, 2013.

Lewis, A. B.; Roche, A. F. \& Wagner, B. Pubertal spurts in cranial base and mandible. Comparisons within individuals. Angle Orthod., 55(1):1730, 1985.

Maurya, R.; Singh, H.; Mishra, H. A. \& Gupta, A. Modified interim mandibular advancement (MIMA) appliance for symptomatic correction of obstructive sleep apnea. J. Clin. Diagn. Res., 10(8):ZH01-3, 2016.

Nilsson, J. J.; Shu, X.; Magnusson, B. H. \& Burt, I. A. Treatment of adolescent patients with class II division 1 malocclusion using Eruption guidance appliance: A comparative study with Twin-block and ActivatorHeadgear appliances. Swed. Dent. J., 40(1):79-89, 2016.

Shirazi, S.; Kachoei, M.; Shahvaghar-Asl, N.; Shirazi, S. \& Sharghi, R. Arch width changes in patients with Class II division 1 malocclusion treated with maxillary first premolar extraction and non-extraction method. J. Clin. Exp. Dent., 8(4):e403-8, 2016.

van Limborgh, J. The role of genetic and local environmental factors in the control of postnatal craniofacial morphogenesis. Acta Morphol. Neerl. Scand., 10(1):37-47, 2012.

Wilhelm, B. M.; Beck, F. M.; Lidral, A. C. \& Vig, K. W. A comparison of cranial base growth in Class I and Class II skeletal patterns. Am. J. Orthod. Dentofacial Orthop., 119(4):401-5, 2001.

Zervas, E. D.; Galang-Boquiren, M. T.; Obrez, A.; Costa Viana, M. G.; Oppermann, N.; Sanchez, F.; Romero, E. G. \& Kusnoto, B. Change in the vertical dimension of Class II Division 1 patients after use of cervical or high-pull headgear. Am. J. Orthod. Dentofacial Orthop., 150(5):771-81, 2016.

\section{Corresponding author: \\ Li Bing \\ Stomatology Hospital \\ Shanxi Medical University \\ 63 Xinjian Road \\ Taiyuan 030001 \\ CHINA}

E-mail: libing-1975@163.com

Received: 06-12-2016

Accepted: 27-02-2017 